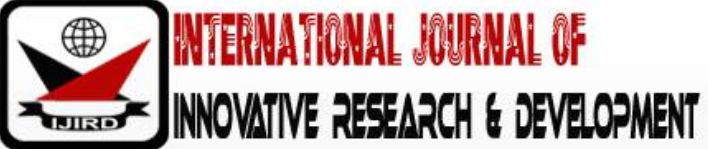

ISSN 2278 - 0211 (Online)

\section{Family Failure and Social Decadence: Issues and Remedies}

Dickay S. A
Lecturer, Department of Educational Foundation,
University of Port-Harcourt Rivers State, Nigeria
Allison, B. R
Lecturer, Department of Sociology,
Federal University Wukari Taraba State, Nigeria
Dickay Q. A
Student, Department of Curriculum, Ignatius Ajuru University of Education
Rumuolumini Port-Harcourt Rivers State, Nigeria

\begin{abstract}
:
Family has been noted and recognized generally as the oldest institution in the history of human existence. Family is "a group consisting of one or more parents, their children and also close relations" family is seen to been the nucleus of any society, whether developed or developing. A family can be seen as people who have both legal and social right to live together, pull its resources together and produces children or offspring two of these adult members conduct a sexual relationship to procreate according to the norms of their society. Types of family include Nuclear, Extended, Monogamous, Polygamous family etc. Characteristics of a family include to finds its origin in marriage, a traditional society, members of the family form an economic unit, cooperating in the productivity and economic stability of the social unit and protection and socialization, security and affectionate interactions with the new members of the family till adulthood. Functions of the family are child bearing, child rearing and protection of the members of the family unit. The specific purpose of the family is the generation, development or formation of the child. Failure can be considered as an illusion especially where a person is incapable of achieving a goal. Social decadence is a process of deterioration or decay of a process. It can be seen as a process of decline or decay in a society, especially in its morals. Remedies parents should take or assume the loving leadership of the family especially the husband. They should ensure their children model their good behaviour. Conclusion, family and parents should try to train and educate their wards from childhood on the need to inculcate a proper moral conscience.
\end{abstract}

Keywords: Family, failure, social, decadence, remedies

\section{Introduction}

Family can be seen as the coming together of a man and woman mostly for the purpose of procreation. It has been regarded as the cornerstone of the society. In both old and modern societies, family has been seen as the most basic unit of social organization and one which shoulders the responsibility of socializing the children. The child is born into the family which forms part of the society. Every society has some generally accepted norms or mores and rules of behavior that are considered right in the group or society if it must function very well. It is a negation of this standard that constitutes decadence. The social and moral decadence in our society has reached a level that calls for concern. There is no respect among the young and the old. They involve in anti-social behavious that are inimical and injurious to the society. Any society that is not morally and socially sound is bound to witness all sorts of social menace and vices.

Youths have abandoned our indigenous culture and tradition and have embraced the western culture completely. Some people blame parents for abandoning their primary role of taking care of the child hence, failed to inculcate good morals and virtues, compassion, respect and other acceptable ways of life. This is because in some homes, both parents are involved in full-time work where the mother returns by $5 \mathrm{pm}$ and the father by $9 \mathrm{pm}$. The child or children are left at the mercy of school teachers, nannies, house maids or house helps who may not play the parental role very well. Others blame the media. The primary role of the media is to inform, educate, entertain and also to serve as the watch-dog of the society but they have succeeded in polluting the minds of people with their videos, movies and some publications and have promoted indecent dressing, drinking alcohol and other dangerous intoxicants, smoking, cultism etc. The youths therefore, dress, talks, misbehave like their unworthy role models with the highest sense of justification. This invariably can lead to a child not paying attention to school work and even drop out of school hence, endangers their productive age and future. 
This paper will therefore, focus on the reasons why we experience failure in families and subsequent decline or decay in the society which culminates to a violation of societal norms and promotion of vices leading to unrest in our homes and societies.

\section{What Is Family}

Family has been noted and recognized generally as the oldest institution in the history of human existence. It is also acknowledged universally as the primary agency of socialization. As defined by Oxford Advanced Learner's dictionary, family is "a group consisting of one or more parents, their children and also close relations" family is seen to be the nucleus of any society, whether developed or developing. It comprises of social units made up of persons united by ties of marriage and blood. Family as a nucleus one is made up of the husband, wife and children. The above describes what sociologist call nuclear family. Beyond the nuclear family, are group of people related by blood such as uncles, aunts, nieces, nephews, etc hence, referred to as extended family.

Therefore, Bremedemieier and Stephenson in Ezewu, (1983) defined family "as a group of related kin, linked by blood and marriage, who occupy a common household and are usually characterized by economic cooperation and solidarity". Further, they stated that a family is formed as a social phenomenon within the frame work of these two ties, blood and marriage. Based on the above, the relationship between members of a family is therefore both biological and social. While the relationship between parents and their children is biological, the one between the parents is purely social since the union or relationship is only possible through socially acceptable or recognized patterns of marriage. From the forgoing, it becomes glaring that every individual belongs to two kinds of families: the one an individual belongs biologically being family of orientation and the one which he/ she belongs socially been the family of procreation. Mardock (1949) in Haranlambos \& Holbor (2008) sees family as "a social group characterized by a common residence, economic cooperation and reproduction. It includes adults of both sexes, at least two of whom maintains a socially approved sexual relationship, and one or more children, own or adopted, of the sexually cohabiting adults"

Therefore, a family can be seen as people who have both legal and social right to live together, pull its resources together and produces children or offspring two of these adult members conduct a sexual relationship to procreate according to the norms of the their society.

\section{Types of Family}

\subsection{Nuclear Family}

Family structure varies from society to society. Nuclear is the smallest family unit which consists of father, mother and children and their children. As noted by Ajuzie (2005:59) Nuclear family refers to "a domestic unit composed of a man and a woman living together in a stable marital relationship, with their dependent children". She maintained that only these two adults are involved in the activities of reproduction of children. The nuclear family is also called a monogamous family where the Man marries and takes his wife to his house to live with her.

\subsection{Extended Family}

Units larger than the nuclear family are usually known as extended families. Such families can be seen as the extensions of the basic nuclear family unit, which can be vertical extensions e.g. the additions of members of the third generation such as spouses' parents. It can also be horizontal extensions such as, the addition of members of the same generation as the spouses. Such as husband's brother, sisters, parents and other relations. " The extended family, unlike the nuclear family, covers the parents of the couple and their children, the brothers and sisters of the parents , the brothers and sisters of the couple and the grand- and great grand children of the couples" Ezewu, (1983:40). This system is predominant in Traditional African society.

\subsection{Monogamous Family}

This is the type or kind of family pattern which is made of up one husband and one wife at a time and their children. This kind of family is synonymous with the nuclear family system.

\subsection{Monandrous Family}

This is almost the opposite of the above. This family pattern or type is based upon a marriage where a woman fetches her husband and takes him home to live with her. In this type of home, the woman is in control and exercises it in full over the man in their household and the children of the marriage belongs to her and bear the name of the woman who customarily is the head of the household.

\subsection{Polygamous Family}

This is a family where a man marries, keeps and controls more than one wife at the same time. This system is practiced in parts of the Traditional African society. It is also acceptable by religions like Islam and Christian denominations or faith. This could be based on economic power or affluence and social influence.

\subsection{Polyandrous Family}

This is also the opposite of polygamy. In this pattern, the woman marries several men or husbands and brings them to her domain. She is the center of attraction and the controller of the household. The children of this association belong to the woman and her lineage. This system is linked to the matrilineal system of marriage. 


\section{Characteristics of a Family}

- It finds its origin in marriage

- It consists of husband, wife and their children. It may surpass the above as other relations may live in the same household in the case of extended family patterns.

- The family members are united together by: Legal bonds, Economic, religious and other kinds of rights and obligations and A precise network of sexual rights and prohibitions

- In a traditional society, members of the family form an economic unit, cooperating in the productivity and economic stability of the social unit.

- Protection and socialization, security and affectionate interactions with the new members of the family till adulthood.

- The family members a strong block against attacks by invaders or enemies.

\section{Functions of the Family}

Family as a social institution is expected to perform some specific functions in the society. We see family as a unit within a larger society charged with the performance of some certain function in the life of the society. Such functions are:

\subsection{Primary Functions of the Family}

This function includes child bearing, child rearing and protection of the members of the family unit. As noted by Ezewu, (1983:41) "child bearing is an important, if not most important precondition for the existence of any society. It is the responsibility of the institution of the family to produce children in order to maintain the continuity of society".

\subsection{Legal Functions}

In the days of ancient Rome and ancient Israel during the patriarchal era, the family had absolute legal power to determine both life and death of every member of the family. But today, the story is different as many societies advocates for the independent rights of the members of the family including legal protection of children against their parents. Hence, the state deals directly with individuals irrespective of his or her position or status in the society.

\subsection{Educational Functions of the Family}

The family by its nature is very important in the development and upbringing of the child hence an important agency of education. The specific purpose of the family is the generation, development or formation of the child. As the initial take-off point of the child, it therefore, implies that the education of the child must start at home and extends to the larger society. Okafor (1981) in Okonkwo and Agada (1991:15) pointed out that "the mother is the great educator because in the education of the infant she is best equipped to combine love with instruction. It is within the affectionate environment of the family that the tender child receives the genesis of his education about the things around him -his new environment and about the realities beyond". Further, they stated that the home is the foundation of a pure and natural education of mankind. Hence, the home is the school of morality and the state. A healthy upbringing in childhood is a good foundation for all future happiness. They maintained that parents should provide role models so that sons and daughters learn by observation what appropriate behavior is for them as male and female.

The interactions of the child or children within this period are usually limited to the family members. This goes a long way to confirm the importance of family in the early education of the child. Researchers have confirmed that about 33\% of the child's educational growth takes places at home before he enters the primary school hence, the saying that home environment is a very significant factor in the child's socialization process.

\subsection{Economic Functions}

The socio-economic status of the family is considered an important aspect in the upbringing of the child. Families play a paramount role in the socialization of the child within the frame work of societal demands. Parents socio-economic status to a greater extent, determines children's ascribe roles and position in the society. Before this era of industrialization in the society, family groups are largely self-supporting economic units, capable of producing most of the things required to keep the family moving such as food, clothing and shelter hence family size was a determinant for what is produced as more hands implies more production.

\section{What Is Failure?}

Failure is the state or condition of not meeting a desirable or intended objective or target. It can be seen as the opposite of success. Failure can be considered an illusion especially where a person is incapable of achieving a goal. It can also be seen as unsuccessful even when an effort was made. Simply put, failure is a deviation from what is expected or desired. Family failure therefore, is a situation where the family or parents are incapable of taking care of the household hence, leading to disunity and state of disarray in the home. Nothing is comparable to joy in the home and harmonious family life.

\section{Causes of Family Failure}

The following are some of the causes of family failure or reasons why some families fail.

- Anti - Christian culture

- Unhappy marriage or cases of domestic violence or abuse

- Divorce 
- Busyness

- Absent father figure

- Lack of discipline/ parental control/ neglect

- Negative media influences

- Balance of work and family

- Lack of communication between husband, wife and children

- Death of one or both parents

- Materialism

- Prolonged ill-health parents

- Full-time of employment of mother

- Financial pressures and poverty

- Lack of knowledge on biblical teaching on marriage and family - Having a good knowledge of God and Christian teaching will help solve some spiritual crises in the home - On this note, Pastors and teachers in the church should always emphasis on God's plan for marriage and the family. Remember your marriage vows: "For better, for worse", "In sickness and in health", "For richer, for poorer...."

- Lack of trust among partners/ suspicion

- Evil company or communication

- Unholy/ unreliable attitude

\section{Social Decadence}

Social relates to people or society or its organization and people living in society and or to the public as an aggregate body. The word decadE Oence is marked by decay or decline relating to or having the characteristics of the decline. It is a process of deterioration or decay of a process. It can be seen as a process of decline or decay in a society, especially in its morals. Decadence could mean a state of falling from a higher standard to a lower state. Decadence can refer to a personal trait, or to the state of a society or part of it. Decadence can also be seen as a deviation from societal norms or set standards by a group and in this case, the society or community.

Every society has a lay down or declaration of rules, regulations, norms, values, beliefs and attitudes considered absolute guides for human behavior. Norms vary according to the environment, situation and culture in which they are found.A negation of these set rules and standards in the society can be considered as social decadence. Social decadence therefore, mean societal decline in abstract sense or decay in standard, morals, dignity, religious faith or skill at governing among the members of the elite of a very large social structure, such as a state or nation. Decadence cannot be separated from morality because it is a negation of the moral standards set in a society to ensure its survival and improve the dignity of man. There must be a set standard or value which is the right attitude expected of every individual in the society. This will guide our judgment to determine if there is a deterioration or decline. It is a society or group that determines the level of decline, decay or decadence.

\section{Some Acceptable Social and Moral Values}

There are some acceptable social and moral standards of behavior in a given society and they are:

Truth, Humility, Loyalty, Goodness, Kindness. Hospitality, Charity, Chastity before marriage, Respect for parents and as well as men and women of honors, dignity of labor and hard work, Sanctity of Human life, Honesty and sincerity, Love for justice, Crave for achievement and Good life

\section{Remedies}

The following remedies could be used as a guide to overcoming family failure hence, reducing the rate of moral and social decadence in the society.

Parents should take or assume the loving leadership of the family especially the husband. They should ensure their children model their good behavior. They should guide the children to grow in the fear of the lord and obey the acceptable societal norms and the main job description for a husband is to love the wife unconditionally as Christ loved the church and gave himself for her (Eph. 5:25). This love will obviously transcend to the children and the society will become a better place. Husbands should learn to practice the servant leadership exemplified by the Lord Jesus.

Parents should not abdicate their primary role or responsibility of building up their homes and families in pursuit of wealth, riches, material things, career, pleasure and fun. They should embrace their duty otherwise; our children will grow to become monsters, deviants and social misfit.

Schools must double their efforts and roles in monitoring of the students. They should go beyond the teacher/ student relationship and sometimes should play the role of fathers and mothers to these children. After all, school is the next socializing agent of the home in the upbringing of these children. With these doubled efforts, the youths will be prevented from being exposed to salacious materials and imitating crimes they watch in films among other insidious items especially in school. Teachers should give adequate attention and create an enabling environment for teaching and learning because it is one of the profitable investments a society can possess to achieve a disciplined and God fearing future leader. Children must be praised for doing good and disciplined or castigated when they do the wrong thing. The fact remains that most of the attitude our children or youths of today display are not innate but acquired. "Train up a child in the way he should go, for when he grows, he will not depart from it" (Prov. 22:6) 
The need to censor what is transmitted in the air waves. We are in a digital world and there is a revolution in the area of Information and Communication Technology (ICT). This internet age has turned the whole world into a global world hence, another big trouble. The internet in the real sense of it was not invented with a bad intent but it has been turned to become a misfortune because the use has been misdirected. Thus, the need for government to monitor the Information and Communication Technology companies with enabling laws to control their activities. They need to censor the contents of what is being transmitted in the airwaves.

Our government must be up and doing and show concern to the well being of the society and its people. They should show commitment, develop new orientations, fresh ideas should be invented and directed towards combating crimes and social vices irrespective of who is involved. Government should overhaul our educational system so that it will have value. Provision of job opportunities will help reduce crime rate as the idle mind is the devil's workshop.

The society as a whole must play a role in curbing this menace. The children and youths of today need guidance counseling which cannot be provided by parents and schools alone. These children go beyond the home and school environment. They need the advice of the old in order to avoid making ill-conceived decisions because the repercussions or resultant effects will be faced by the society in general. Training the youths therefore, should be a collective responsibility of the members of the society. If they are properly trained, we will have peace both in the home, school, church and the entire society will be a good place to live.

The church as one of the agents of socialization should also teach the children good morals and ensure they lead by examples. They should stand out as role models. Children learn faster by imitation and would prefer what appeals to them most. Our teachers and pastors should bring or train up the children by teaching them good morals and displaying good conduct and character that will be worthy of emulation.

\section{Conclusion}

Family and parents should try to train and educate their wards from childhood on the need to inculcate a proper moral conscience. They should live in the fear of the Lord and show love to each other.Both the school, government and church should play their roles to enhance a sustainable society and a better future for all.

\section{References}

i. Ajuzie, M.V. [2005] Introduction to Sociology of Education. DMMM (Project T.I.M.E) Lagos, 2, Morunfolu Street, Akoka.

ii. Ezewu, E.E. (1983). Sociology of education. Nigeria, London Nigeria Ltd.

iii. Haralanbos and Holborn (2008) Sociology: Themes and Perspectives. London, Harper Collins publisher Ltd.

iv. Okonkwo and Agada (1991)(ed): Sociology of Educational for Nigeria. Owerri, Total publisher Ltd.

v. Oxford Advanced Learners Dictionary. 